\title{
PRODUCTION OF MODIFIED SORBENT BASED ON PEACH SHELLS
}

\author{
Aigul Mamyrbekova ${ }^{1, \bowtie}$, A.D. Mamitova ${ }^{2}$, Aizhan Mamyrbekova ${ }^{1}$, \\ M.K. Kassymova ${ }^{3}$, G.S. Mutasheva ${ }^{4}$ and D. Tanatar ${ }^{5}$ \\ ${ }^{1}$ Department of Laboratory Disciplines, Faculty of Dentistry, Khoja Akhmet Yassawi \\ International Kazakh-Turkish University, Turkestan 161200, Kazakhstan \\ ${ }^{2}$ Department of Life Safety and Environmental Protection, Faculty of Construction and \\ Transport, Auezov South-Kazakhstan University, Shymkent 160012, Kazakhstan \\ ${ }^{3}$ Department of Chemistry, Natural Scientific and Pedagogical Higher School, Auezov South \\ Kazakhstan University, Shymkent 160012, Kazakhstan \\ ${ }^{4}$ Department of Ecology, Faculty of Agrobiology, Kazakh National Agrarian Research \\ University, Almaty 050010, Kazakhstan \\ ${ }^{5}$ Student of group 303c, Faculty of Dentistry, Khoja Akhmet Yassawi International Kazakh- \\ Turkish University, Turkestan 161200, Kazakhstan \\ ${ }^{\square}$ Corresponding Author: aigul.mamyrbekova@ayu.edu.kz
}

\begin{abstract}
The possibility of sorbent obtaining from the waste of plant origin, the peach shell, is considered. The physicochemical characteristics of the modified sorbents made from peach shells and their applications for purifying gas-air mixtures and sewage from toxic compounds are studied. According to preliminary data, the heat-treated peach shell, used as a sorbent and filter, is an effective cheap and available material for the treatment of wastewater and gas emissions. The complex of classical and modern methods of analysis is considered and characterized: elemental analysis, differential thermal, IR spectroscopic, X-ray structural, as well as other methods of study of physical-chemical and structural sorption properties. Based on experimental results, it was established that the sorbent on the base of modified sorbent prepared by chemical modification, followed by thermal activation in the atmosphere of carbon dioxide, has a porous structure.
\end{abstract}

Keywords: Activated Carbon, Peach Shell, Adsorption, Modified Sorbent, Wastewater Treatment.

RASĀYAN J. Chem., Special Issue, 2021

\section{INTRODUCTION}

Introduction into the industry of scientific and technical developments aimed at improving the quality of activated coals, increasing their assortment, and using various types of raw materials allows solving the problem of satisfying the needs for quality activated coals. ${ }^{1}$ A considerable amount of activated coal is now needed to solve environmental problems - the preparation of drinking water ${ }^{2}$, treatment of wastewater and gas emissions ${ }^{3}$, recuperation of vapors of organic compounds ${ }^{4}$, separation of process gases. ${ }^{5}$ Intensification of processes of chemical, petrochemical and biotechnological industries requires significant mechanical strength of coal adsorbents.

Adsorption and ion exchange processes on solid sorbents are used for wastewater purification from various toxicants and many other applications. ${ }^{6-9}$ Both new adsorbents (e.g. highly efficient activated coals) and new ion-exchange materials (e.g. selective cation sites) are systematically developed. ${ }^{10-14}$ The actual task is to create the multifunctional sorbents that are simultaneously able to adsorb the nonpolar substances due to van der Waals interaction and to adsorb the metal ions by oxygen-containing functional groups the ion exchange mechanism. The use of multifunctional sorbents would significantly simplify the scheme of waste-water treatment, as waste water of industrial enterprises contains, as a rule, a lot of pollutants of different nature (petroleum products, heavy metal ions, surfactants, etc.), because multifunctional sorbents possess the advantages of activated coal and ion-exchange resins. ${ }^{15-17}$

Rasayan J. Chem., 31-39, Special Issue (2021)

http://doi.org/10.31788/RJC.2021.1456618

This work is licensed under a CC BY 4.0 license. 
At present, the theoretical issues related to the purposeful formation of the corresponding active centers on the surface of the sorbent are insufficiently studied. The laws of sorption of various substances on the surface of multifunctional sorbents have not been studied. The possibility of parallel processes of adsorption and ion exchange can lead to a significant change in the kinetic and equilibrium characteristics compared with mono-functional sorbents (activated coals, ion-exchange resins, etc.). Therefore, studies of the properties of multifunctional sorbents are not only of practical interest but also have scientific significance.

It is known that highly active adsorbents can be obtained from plant raw materials (wood, seeds of fruit trees, etc.) by carbonization and activation. ${ }^{18,19}$ For the obtained adsorbents (activated coals), ionexchange properties are uncharacteristic.

As the alternative can be the sorbents obtained by heating vegetable raw materials in the air. The surface of such sorbents can further be modified to allow them to adsorb the metal ions by an ion-exchange mechanism. Recently, more and more attention has been paid to carbon sorbents of natural and artificial origin and sorbents produced from the waste of vegetable raw materials obtained by burning in the air at relatively low temperatures. There are industrial sorbents based on active coals, which are obtained from various types of organic raw materials: anthracite, peat, wood and products of its processing, materials of animal origin. In Europe, several producers obtain durable activated carbon from the shells of coconut and hazelnuts and olive seeds. ${ }^{20}$ Non-traditional raw materials, which have not found wide application yet in the industry, can be the shells of various fruit trees (apricot, peach, plum, cherry), grape seeds, nutshells, which are waste products. ${ }^{21}$ In preliminary experiments, it was found that the raw material for obtaining cheap and available multifunctional sorbents can be the peach shell.

According to world practice the food enterprises annually produce significant amounts of waste of peach fruits processing production, which are widely cultivated on the territory of the Southern countries. This waste can serve as an excellent raw material for the production of activated coal. ${ }^{22}$ There is enough detailed information about the processing of fruit shells into valuable products, but the literature data on the production and use of coal sorbents based on the shell are few. ${ }^{23}$

The physical and chemical characteristics of the burnt peach shells and the materials obtained during their subsequent oxidation by chemical reagents have not been previously investigated. The laws of sorption of different substances on sorbents obtained from the peach shell are also unknown. The relevant research can become the basis for new technologies of treatment of wastewater and gas emissions from a wide range of pollutants.

In connection with the above, it is highly desirable to develop a method for obtaining a modified sorbent based on the stones of fruit trees. We hypothesized a completely different approach to solving the problem. Instead of using imported expensive adsorbents, obtaining a modified sorbent from plant raw materials is proposed. The proposed sorbent technology has several features that distinguish it from sorbents of the classical type: high chemical resistance and increased mechanical strength at high porosity.

The solution to the problem of developing a technology for producing modified activated carbon based on local production waste, with a preliminary study of their physical and chemical properties and activation of adsorption properties in a given direction, associated with obtaining particularly active centers on the surface, should ensure the improvement of the technical and economic performance of the relevant industries, reducing environmental pollution, and is of great economic, social and environmental importance.

This work is devoted to the development of technology for producing modified activated carbon based on peach seed shells and technology for its use in natural and wastewater treatment processes and gas emissions, which would meet modern production requirements and the conditions for bringing the degree of purification and quality of treated streams to the level of discharge into reservoirs and emission into the atmosphere, or their reuse.

\section{Chemicals, Reagents and Materials}

\section{EXPERIMENTAL}

In work, as raw material, peach shells are used. All the reagents $\left(\mathrm{H}_{2} \mathrm{SO}_{4}, \mathrm{HCl}, \mathrm{H}_{3} \mathrm{PO}_{4}\right.$ and $\left.\mathrm{ZnCl}_{2}\right)$ used were of analytical grade or better. In order to avoid contamination during the chemical reactions, distilled water was used throughout the synthesis. 


\section{Preparation of Modified Sorbent}

For the chemical activation of peach shells, the equipment consisting of an activation flask, electric heater, reverse refrigerator and thermometer was used. ${ }^{24-26}$ Prior to chemical treatment, the mechanoactivated shell was sifted through a sieve of $0.1 \mathrm{~mm}$. Further, the chemical activation of the shell was carried out by sulfuric, hydrochloric, phosphoric acids and zinc chloride. After the samples were washed by distilled water and dried at $378 \mathrm{~K}$ in a drying cabinet for 2 hours. Then the shell was cooled in a desiccator and placed into flasks with rubber stoppers.

Thermal activation of peach shells was carried out in a furnace for activation in the atmosphere of carbon dioxide. ${ }^{27-29}$ The temperature of the furnace was measured by a platinum-rhodium-platinum thermocouple, regulated by a thermoregulator of the type ERM-47. Activation was carried out at temperatures $573-1273 \mathrm{~K}$, heating at each temperature for $1-4$ hours. Heat-treated samples of peach shells before measuring their adsorption properties were preserved in hermetic conditions.

\section{Experimental Characterization of Modified Sorbent}

The complex classical and modern methods of analysis were used for the study: elemental analysis, differential thermal, IR spectroscopic, as well as other methods of studying of physical and chemical properties. To solve the tasks the research methods based on the study of individual laws were chosen.

Elemental analysis was carried out on the EA-1108 analyzer produced by Carlo Erba (Italy). ${ }^{30-32}$ Scanning electron microscopy (SEM) was used to research the changes in the structure of the peach shell surface. High-resolution images were obtained by using of the JEM-2010 electron microscope. The obtained data after each processing stage were analyzed with the help of SEM. Surface changes in the morphology and structure of materials were studied.

Differential thermal analysis was carried out on the Q-derivatograph of MOM company (Hungary). The recording was carried out at a heating rate of $10 \mathrm{~K} / \mathrm{min}$ with constant weighing, the value was selected depending on the depth of thermal effects. ${ }^{33}$

Infrared spectroscopic analysis of peach shell samples was carried out on the SPECORD device. ${ }^{34}$ Spectra were taken: abscissa spectra scale - normal with factor 2, i.e. $7.5 \mathrm{~mm} / 100 \mathrm{~cm}^{-1}$, recording time - 4.4 $\mathrm{min} / \mathrm{sheet}$, wavenumber region - $(400-4000) \mathrm{cm}^{-1}$.

Diffraction studies were carried out on the X-ray diffractometer Dron-3.

\section{RESULTS AND DISCUSSION}

Preliminary analysis of works aimed at the study and research of peach shells to obtain modified adsorbents show that peach shells are the most common in the Central Asian region and outstripping by structural and sorption characteristics the other types of fruit shells. ${ }^{35-38}$ Therefore, in work as a raw material the peach shells are used. The shell of peach and apricot, plum, and walnut differ significantly in their anatomical structure from the wood. Its mechanical tissue consists of stony cells that do not have a fibrous form and is characterized by a very thick lignified shell and the destroyed protoplast (Fig.-1).

To determine the separate elements of the peach shell, elemental analysis was carried out, which showed that the shell consists of carbon (76\%), hydrogen (23.586\%), and nitrogen $(0.372 \%)$ (Fig.-2). The qualitative evaluation of the thermograms was made based on the DTA and DTG curves (Fig.-3). In this case, the first peak of the differential thermogravimetric analysis curve indicates a process occurring with mass reduction.

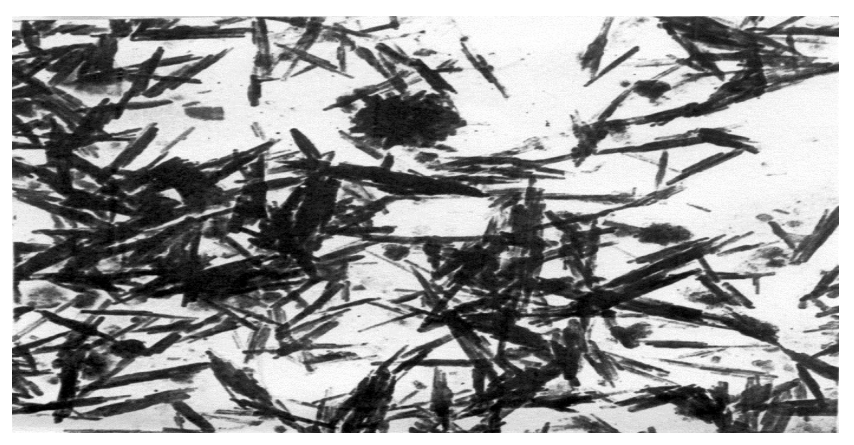

Fig.-1: Electron Microscopic Photograph of the Peach Shell (x1000) 
RASĀYAN J. Chem.

31-39| Special Issue | 2021

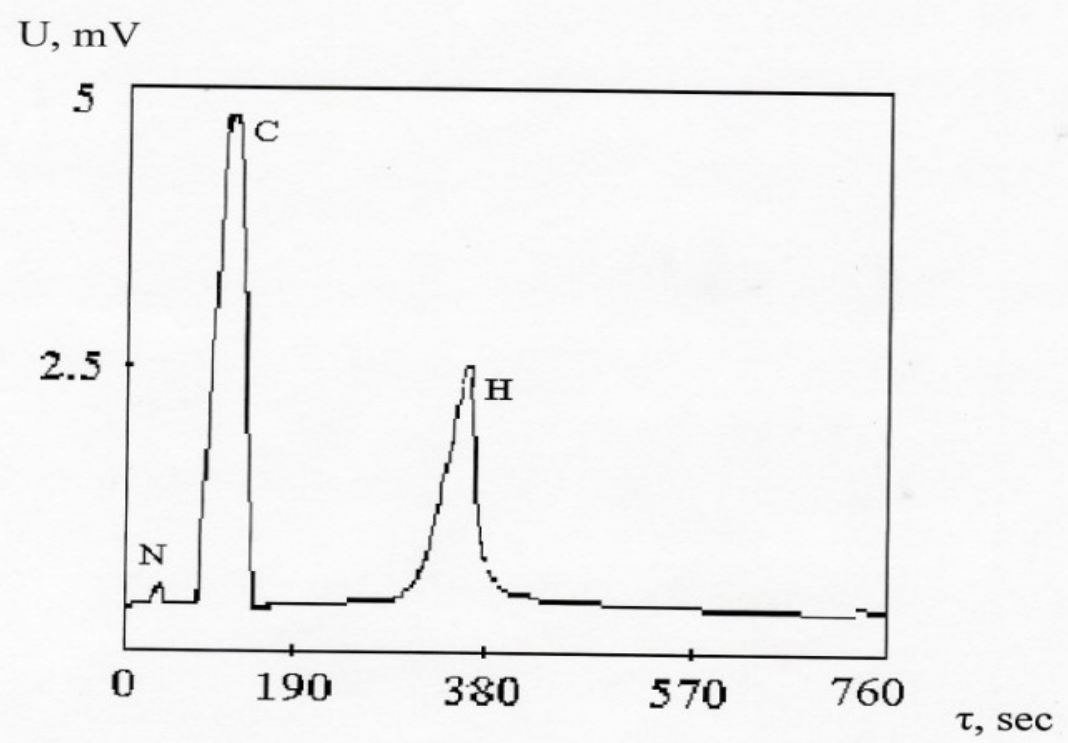

Fig.-2: Elemental Analysis

As can be seen, this mass reduction begins at a temperature of $294 \mathrm{~K}$, reaches its maximum speed at 378 $\mathrm{K}$, and ends at about $423 \mathrm{~K}$. On the curve of differential thermal analysis in the specified temperature range $(378 \mathrm{~K})$ there is also a peak of a similar shape based on which it can be established that this process is endothermic. In the mentioned temperature range, the content of mechanically or adsorptive-connected water is removed from the sample and this process causes a decrease in mass.

The second peak of the curve of differential- thermal gravimetric analysis $(540 \mathrm{~K})$ means a decrease in mass, based on which it can be concluded that there is not a single process. The culminating point is created in such a way that the organic matter decomposes into two different components sequentially and before the full decomposition of one component, the decomposition of the second component begins. Thus, the curve was formed as a result of two decomposition processes. Decomposition reaches a maximum rate at $540 \mathrm{~K}$ and $578 \mathrm{~K}$ and ends at $635 \mathrm{~K}$.

By comparing the curves of differential-thermal and differential - thermogravimetric analyses, the thermal reactions occurring in the sample were evaluated simultaneously from two sides in terms of enthalpy and mass change. Both curves show changes, but their shapes are different. This circumstance indicates that the curve of differential thermal analysis is formed due to the summation of thermal effects of several physical and chemical transformations.

At the analysis of the curve of differential thermal analysis, it turns out that in the temperature range 606 $\mathrm{K}$, particular reactions are partly endothermic and partly exothermic processes. The differential thermal analysis curve shows the resultant of these thermal effects with the opposite sign. The occurrence of such a thermal effect is explained by the fact that the rupture of valence forces in organic compounds is accompanied by heat absorption, while the release of heat accompanies recombination and the formation of new compounds.

The course of endothermic effects is characteristic for the curve of differential thermogravimetric analysis, i.e. the change in the rate of rupture of valence bonds and the removal of gaseous fragments of $\mathrm{H}_{2}, \mathrm{CO}, \mathrm{CO}_{2}, \mathrm{CH}_{4}$.

The quantitative evaluation of the thermograms was made based on the curve of thermogravimetric analysis (TG) (Fig.-3). In this case, due to the overlap of reactions, it is difficult to determine by the TG curve which part of the observed change relates to one reaction and which to the second of the following reactions. The DTG curve shows the minimum of the points at which one reaction almost finishes and the second one begins (for example, $\mathrm{T}=294 \mathrm{~K}$ and $440 \mathrm{~K}$ ), so by projecting these points onto the $\mathrm{TG}$ curve, it is easy to establish the values of mass change related to individual reactions.

The review of the IR spectra of peach shell, chemically-activated and chemically-thermally activated peach shells in the range from $400 \mathrm{~cm}^{-1}$ to $3200 \mathrm{~cm}^{-1}$ makes it possible to suggest that all samples contain 
RASĀYAN J. Chem.

31-39| Special Issue | 2021

amino compounds (Fig.-4), which follows from the position and intensities of the corresponding absorption bands in the spectra.

Thus, the intensive absorption band with a maximum of $\sim 690 \mathrm{~cm}^{-1}$ is caused by deformation oscillations of multiple $(\mathrm{C}=\mathrm{C})$ bonds. Low-intensity absorption maxima ranging from $700 \mathrm{~cm}^{-1}$ to $950 \mathrm{~cm}^{-1}$ should also be attributed to deformation CH-bonds. Fluctuations of low intensity in the region $(1000-8500) \mathrm{cm}^{-1}$ are observed in the spectra of unsaturated hydrocarbons.

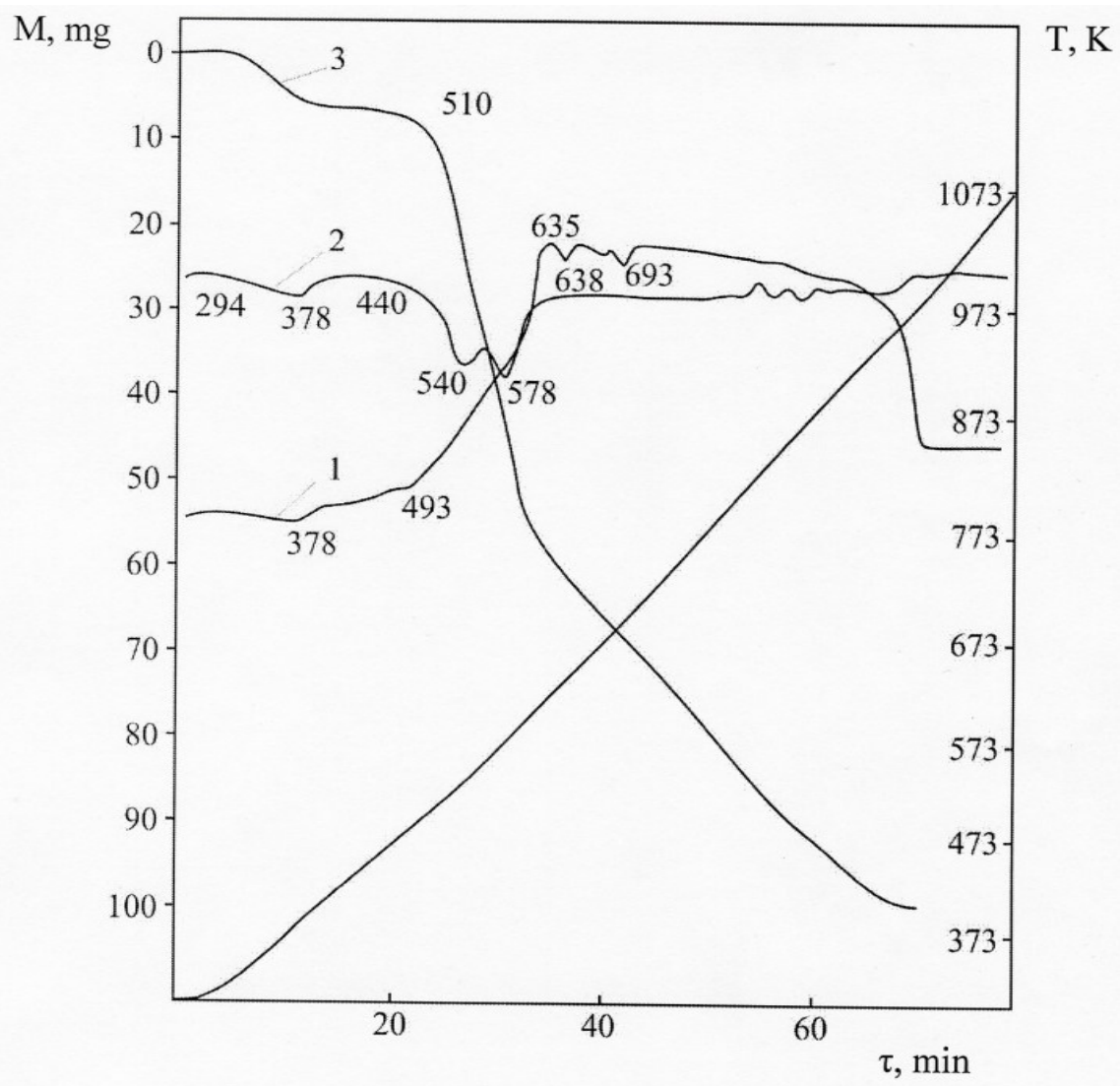

Fig.-3: Differential-thermal, Differential-thermogravimetric and Thermogravimetric Analyses Curves: 1-DTA; 2-DTG; 3-TG.

By deformation oscillations of the multiple hydrocarbon bond $(\delta: \mathrm{CH}$ and $\beta: \mathrm{CH})$, the appearance of absorption maxima at (1274-1240) $\mathrm{cm}^{-1}$ and $1103 \mathrm{~cm}^{-1}$, respectively, is caused. Low-intensity absorption at $3100 \mathrm{~cm}^{-1}$ also corresponds to valence oscillations of $\mathrm{CH}$-groups.

The appearance of absorption maxima in the spectra at $(2670-2610) \mathrm{cm}^{-1}$ and $1681 \mathrm{~cm}^{-1}$ (observed only in the peach shell spectrum) is caused by the hydrogen bond oscillations in the $\mathrm{NH}_{2}$ group.

Absorption maxima of insignificant intensity at $1543 \mathrm{~cm}^{-1}$ and $520 \mathrm{~cm}^{-1}$ are due to $(\mathrm{C}=\mathrm{C})$-group oscillations.

The medium intensity band at $2280 \mathrm{~cm}^{-1}$ (sample of chemically activated peach shells) appears in the spectrum due to oscillations of $\mathrm{C} \equiv \mathrm{N}$ groups with a triple bond. The splitting of this band into two maxima (peach shell spectrum) indicates the formation of 2 energetically unequal types of bonds.

The bands of strong intensity are marked on the figure by * identify the spectrum of vaseline oil.

IR spectroscopy data are consistent with elemental and thermal analyses. Studies of characteristics have shown the advantages of peach shells: their low cost, transportability, environmental friendliness, and high prevalence in the Central Asian region.

The results of X-ray analysis show that the main components of the shell are fiber and amino acids. The corresponding reflection evidences fiber's presence in the shell to the interplane distance in $(6,625 ; 1,804$; $2,265 ; 2,78) \mathrm{nm}$. In addition, the characteristic of amino acid lines are well expressed: $(1,47 ; 1,57 ; 1,981$; $2,52) \mathrm{nm}$. 
RASĀYAN J. Chem.

31-39| Special Issue | 2021

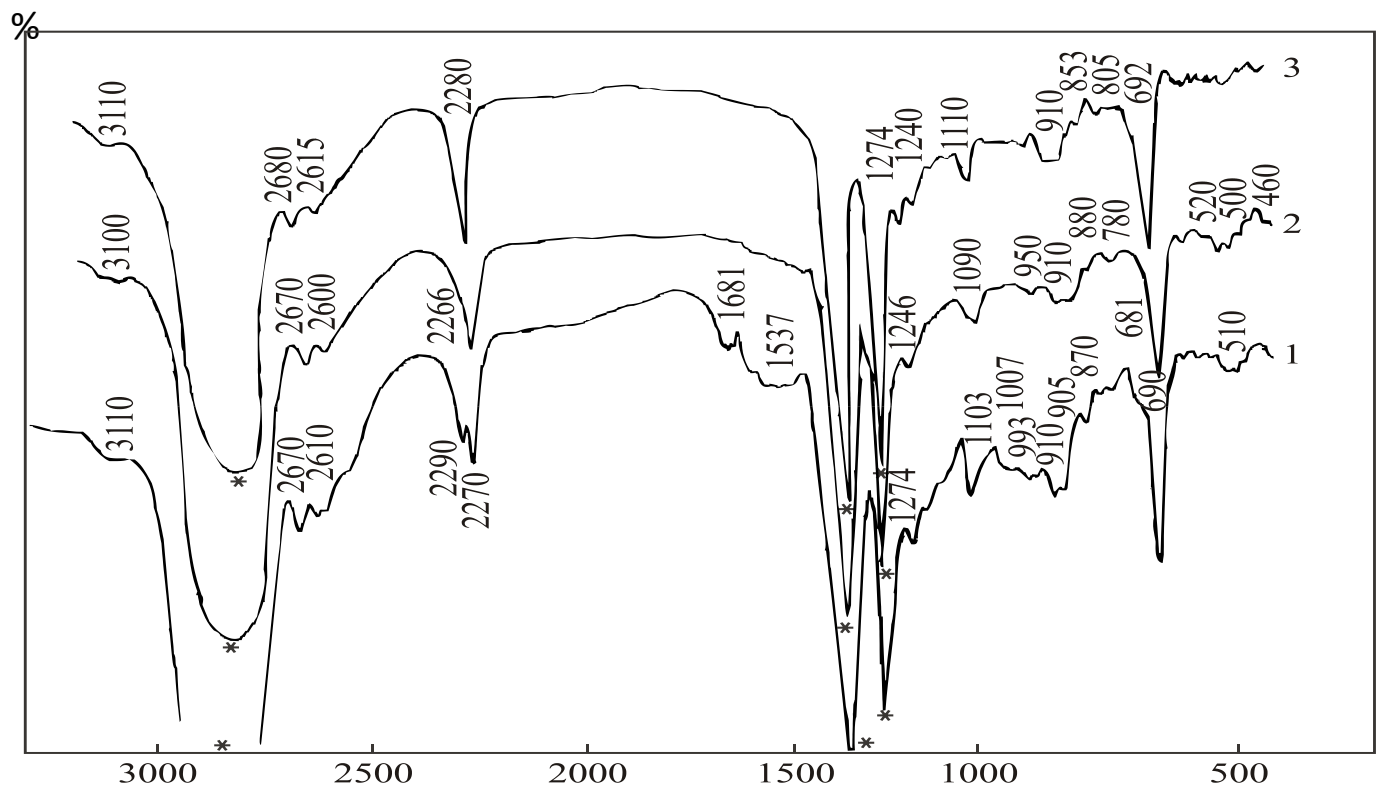

Fig.-4: IR Spectra of Peach Shell: Designation of Curves: 1 - Peach Shell; 2 - Chemically-activated Peach Shell; 3 - Chemically-thermally-activated Peach Shell.

Radiographs of the shell are shown on Fig.-5. Analysis of the obtained radiographs shows that the rich by reflexes pattern indicates the presence of amino acids $(1,46 ; 1,57 ; 1,98 ; 2,52) \mathrm{nm}$ and carbon $(1,69 ; 2,02$; $3,38) \mathrm{nm}$ in chemically-activated shell; and the presence of amino acids $(1,46 ; 1,57 ; 1,98 ; 2,52) \mathrm{nm}$ and carbon $(1,69 ; 2,02 ; 3,38) \mathrm{nm}$ in chemical-thermally-activated shell.

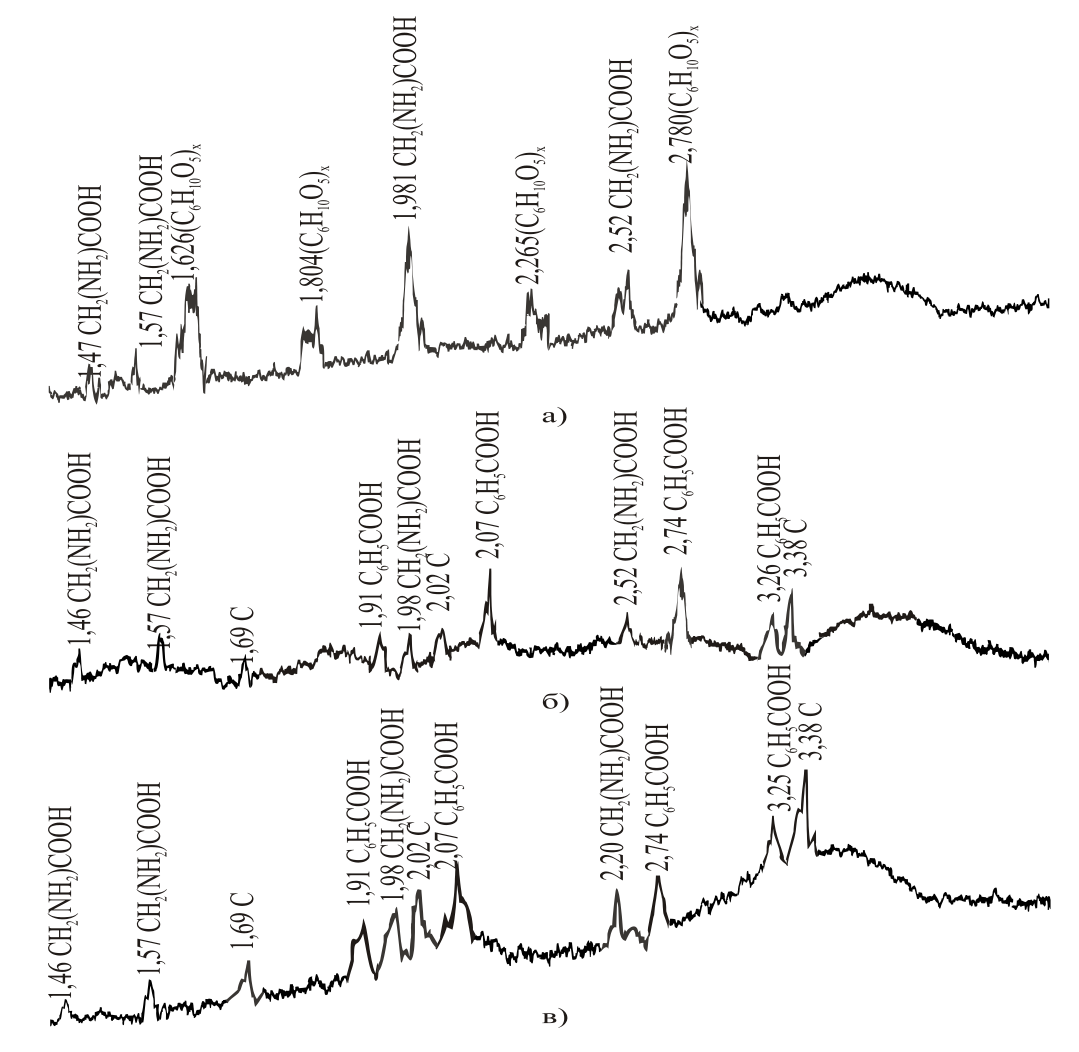

6462605856545250484644424038363432302826242220181614

Fig.-5: X-ray analysis curves: a) X-ray photograph of the shell; b) X-ray photograph of chemically activated shell; c) X-ray photograph of the chemical-thermally-activated shell. 
Based on experimental results, it was established that the sorbent on the base of modified sorbent prepared by chemical modification, followed by thermal activation, has a porous structure.

The results of the Scanning Electron Microscopy (SEM) are shown in Fig.-6 and 7. SEM characterization (Fig.-7) indicates that the modified sorbent has discrete porous nature with variable wall thicknesses and pore sizes. This SEM data could be interpreted to the morphological features of the material, such as bulges in the other wall, the channel structure of macrospores, which are characteristic of a surface structure of the carbonized peach shells.

Activated coals formed the following series by developing a porous structure: treated $\mathrm{ZnCl}_{2}$ and $\mathrm{CO}_{2}>$ treated $\mathrm{ZnCl}_{2}>$ treated $\mathrm{H}_{2} \mathrm{SO}_{4}>$ treated $\mathrm{HCl}>$ treated $\mathrm{H}_{3} \mathrm{PO}_{4}$. According to the research results, it is clear that $\mathrm{ZnCl}_{2}$ is the best activator, so in further work, activation was carried out using It. For samples treated with acids, the optimal parameters of the activation mode are concentration - 30\%; time - 2 hours. For samples treated with $\mathrm{ZnCl}_{2}$, the optimal parameters of the activation mode are: impregnation coefficient 0.4; time - 3 hours. For samples treated with $\mathrm{ZnCl}_{2}$ followed by $\mathrm{CO}_{2}$ activation, the optimal parameters are $\mathrm{CO}_{2}$ temperature - $773 \mathrm{~K}$; impregnation coefficient 0.4 . The studies were carried out with the ratio of adsorbent and absorbate equal to 1:200.

The study of the effect of thermal activation on the adsorption-structural characteristics of peach shells showed that the most developed porous structure is observed at the activation temperature in the $\mathrm{CO}_{2}$ stream $973 \mathrm{~K}$ and the activation time of 4 hours. Experimental results indicate the effectiveness of heat treatment of peach seed shells, which have a large volume of micropores $6.0 \cdot 10^{-4} \mathrm{~m}^{3} / \mathrm{kg}$ and a moderately developed transition porosity of $2.0 \cdot 10^{-4} \mathrm{~m}^{3} / \mathrm{kg}$.

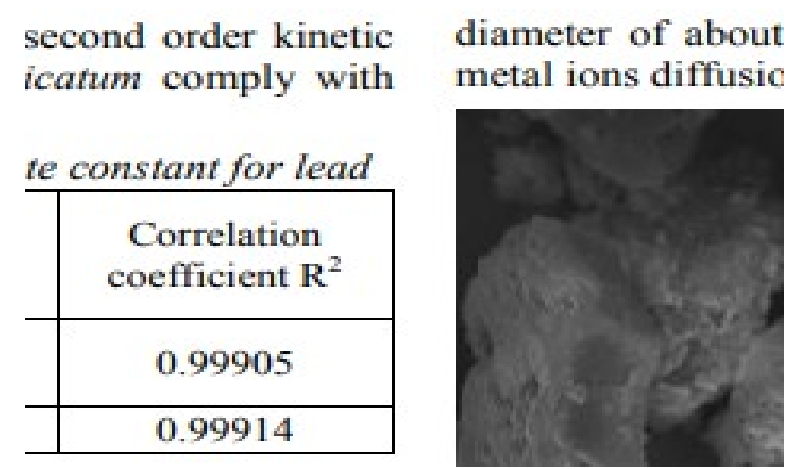

Fig.-6: Scanning Electron Microscope (SEM) image of the Ground Peach Shell Surface (x 1000)

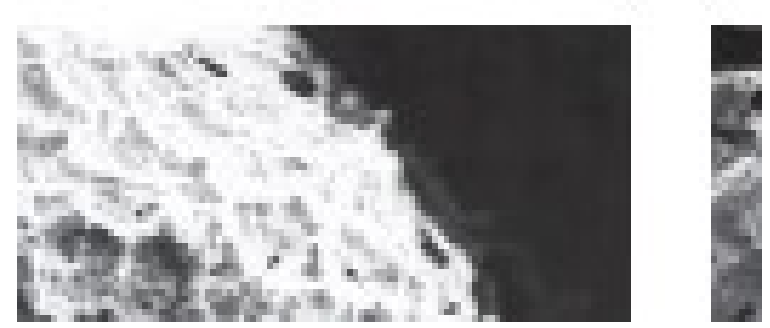

Fig.-7: Scanning Electron Microscope (SEM) image of the Sorbent Carbonized at 743 K (x 1000)

\section{CONCLUSION}

Thus, the complex of classical and modern methods of analysis is considered and characterized: elemental analysis, differential thermal, IR spectroscopic, X-ray structural, as well as other methods of study of physical-chemical and structural sorption properties. 
RASĀYAN J. Chem.

31-39| Special Issue | 2021

According to the results of elemental analysis, it was found that the shell of peach consists of carbon (76\%), hydrogen $(23.586 \%)$ and nitrogen $(0.372 \%)$. According to the obtained thermogravimetric analysis, it can be seen that up to a temperature of $423 \mathrm{~K}$ there is a loss of mass due to the removal of adsorbed water. At a temperature of $463 \mathrm{~K}$, the decomposition of the shell begins with the release of volatile products, which is accordingly accompanied by a change in its mass. The mass loss ends at 973 $\mathrm{K}$. IR spectroscopy data are consistent with elemental and thermal analyses.

Studies of characteristics have shown the advantages of peach shells: their low cost, environmental friendliness, and high prevalence in the Central Asian region.

\section{REFERENCES}

1. J. Wang, C. Chen, Biotechnology Advances, 27, 195(2009), https://doi.org/10.1016/j.biotechadv.2008.11.002

2. G.F. Viana, K.S. Garsia, J.A. Menezes-Filho, Environmental Monitoring and Assessment, 181, 255(2011), https://doi.org/10.1007/s10661-010-1827-3

3. P.B. Tchounwou, C.G. Yedjou, A.K. Patlolla, D.J. Sutton, Molecular, Clinical and Environmental Toxicology, 101, 133(2012), https://doi.org/10.1007/978-3-7643-8340-4_6

4. M.A. Shaheen, R. Akram, A. Karim, T. Mehmood, R. Farooq, Sh.Iqbal, M. Iqbal, Pakistan $\begin{array}{llll}\text { Journal of Analytical \& Environmental Chemistry, } & \text { 17, }\end{array}$ https://doi.org/10.21743/pjaec/2016.06.012

5. A. Saghatelyan, L. Sahakyan, O. Belyaeva, N. Maghakyan, Journal of Atmospheric Pollution, 2, 12(2014), https://doi.org/10.12691/jap-2-1-3

6. D.S. Malik, C.K. Jain, Applied Water Science, 7, 2113(2017), https://doi.org/10.1007/s13201-016-0401-8

7. G. Alagumuthu, M. Rajan, Chemical Engineering Journal, 158, 451(2010), https://doi.org/10.1016/j.cej.2010.01.017

8. G. Crini, E. Lichtfouse, L. Wilson, N. Morin-Crini, Environmental Chemistry for a Sustainable World, 18, 23(2018), https://doi.org/10.1007/978-3-319-92111-2_2

9. S. Babel, T.A. Kurniawan, Journal of Hazardous Materials, 97, 219(2003), https://doi.org/10.1016/s0304-3894(02)00263-7

10. D. De Quadros Melo, V. De Oliveira Sousa Neto, F.C. De Freitas Barros, G.S. Raulino, C.B. Vidal, R.F. Do Nascimento, Journal Applied Polymer Science, 133, 1(2016), https://doi.org/10.1002/app.43286

11. P. Devi, A.K. Saroha, Science of The Total Environment, 578, 13(2017), https://doi.org/10.1016/j.scitotenv.2016.10.220

12. R. Dhankhar, A. Hooda, Environmental Technology, 32, 467(2011), https://doi.org/: 10.1080/09593330.2011.572922

13. L. Ramrakhiani, S. Ghosh, S. Majumdar, Applied Biochemistry and Biotechnology, 180, 41(2016), https://doi.org/10.1007/s12010-016-2083-y

14. S. Tamrakar, R. Verma, S.K. Sar, Ch. Verma, Rasayan Journal of Chemistry, 12(2), 455(2019), https://doi.org/10.31788/RJC.2019.1225106

15. H. Revathi, A. Xavier, M.D. Kumar, T. Saranya, A. Kaviyarasu, T. Murugan, Rasayan Journal of Chemistry, 12(2), 719(2019), https://doi.org/10.31788/RJC.2019.1225094

16. K. Venkata Pravalika, P. Janaki Sriram, P. Karunasri Meghana, K. Ravindhranath, Rasayan Journal of Chemistry, 11(4), 1750(2018), https://doi.org/10.31788/RJC.2018.1145048

17. S.A. Bushumov, T.G. Korotkova, Rasayan Journal of Chemistry, 13(4), 1619(2020), https://doi.org/10.31788/RJC.2020.1335454

18. S. Prakash Chandar, K. Gunasekaran, Rasayan Journal of Chemistry, 12(3), 1038(2019), https://doi.org/10.31788/RJC.2019.1235233

19. Aizhan Mamyrbekova, A.D.Mamitova, M.K.Kassymova, Aigul Mamyrbekova, Zh.E. Daribayev, R.E. Pralieva, Rasayan Journal of Chemistry, 13(4), 2332(2020), https://doi.org/10.31788/RJC.2020.1345761 
RASĀYAN J. Chem.

31-39| Special Issue | 2021

20. S.A. Dastgheib, D.A. Rockstraw, Carbon, 39, 1849(2001), https://doi.org/10.1016/S00086223(00)00315-8

21. E. Dermibas, N. Dizge, M.T. Sulak, M. Kobya, Chemical Engineering Journal, 148, 480(2009), https://doi.org/10.1016/j.cej.2008.09.027

22. M. Stojanovic, Z. Lopicic, J. Milojkovic, C. Lacnjevac, M. Mihajlovic, M. Petrovic, A. Kostic, Journal of Engineering \& Processing Management, 10, 231(2018), https://doi.org/10.7251/JEPM1810034L

23. C. Namasivayam, D. Sangeetha, Journal of Hazardous Materials, 135, 449(2006), https://doi.org/10.1016/j.jhazmat.2005.11.066

24. P. Nowicki, J. Kazmierczak, R. Pietrzak, Powder Technology, 269, 312(2015), https://doi.org/10.1016/j.powtec.2014.09.023

25. D. Angin, E. Altintig, T.E. Ko“se, Bioresource Technology, 148 542(2015), https://doi.org/10.1016/j.biortech.2013.08.164

26. D. Adinata, W.M. WanDaud, M.K. Aroua, Bioresource Technology, 98, 145(2007), https://doi.org/ 10.1016/j.biortech.2005.11.006

27. M.P. Elizalde-González, J. Mattusch, A.A. Peláez-Cid, R. Wennrich, Journal of Analytical and Applied Pyrolysis, 78, 185(2007), https://doi.org/10.1016/j.jaap.2006.06.008

28. T. Uysal, G. Duman, Y. Onal, I.J. Yasa, Journal of Analytical and Applied Pyrolysis, 108, 47(2014), https://doi.org/10.1007/s10973-015-4966-5

29. A. Ould-Idriss, M. Stitou, E.M. Cuerda-Correa, C. Fernández-González, A. Macías-García, M.F. Alexandre-Franco, V. Gómez-Serrano, Fuel Processing Technology, 92, 266(2011), https://doi.org/10.1016/j.fuproc.2010.05.018

30. N. Ozbay, A.S. Yargic, Journal of Applied Chemistry, 23, 826(2016), https://doi.org/10.1155/2016/8236238

31. Y.X. Wang, H.H. Ngo, W.S. Guo, Science of the Total Environment, 533, 32(2015), https://doi.org/10.1016/j.scitotenv.2015.06.087

32. W. Tongpoothorn, M. Sriuttha, P. Homchan, S. Chanthai, C. Ruangviriyachai, Chemical Engineering Research and Design, 89, 335(2011), https://doi.org/10.1016/j.cherd.2010.06.012

33. Sh. Amerkhanova, R. Shlyapov, A. Uali, Colloidal Surfactants A, 532, 36(2017), https://doi.org/10.1016/j.colsurfa.2017.07.015

34. C. Saka, Journal of Analytical and Applied Pyrolysis, 95, 21(2012), https://doi.org/10.1016/j.jaap.2011.12.020

35. D. Ozcimen, A. Ersoy-Mericboyu, Journal of Hazardous Materials, 168, 1118(2009), https://doi.org/10.1016/j.jhazmat.2009.02.148

36. J. Saleem, U.B. Shahid, M. Hijab, H. Mackey, G. McKay, Biomass Conversion and Biorefinery, 9 , 775(2019), https://doi.org/10.1007/s13399-019-00473-7

37. G.Z. Kyzas, E.A. Deliyanni, Chemical Engineering Research and Design, 97, 135(2015), https://doi.org/10.1016/j.cherd.2014.08.020

38. M. Kilic, E. Apaydin-Varol, Applied Surface Science, 261, 247(2012), https://doi.org/10.1016/j.apsusc.2012.07.155

[RJC-6618/2021] 